
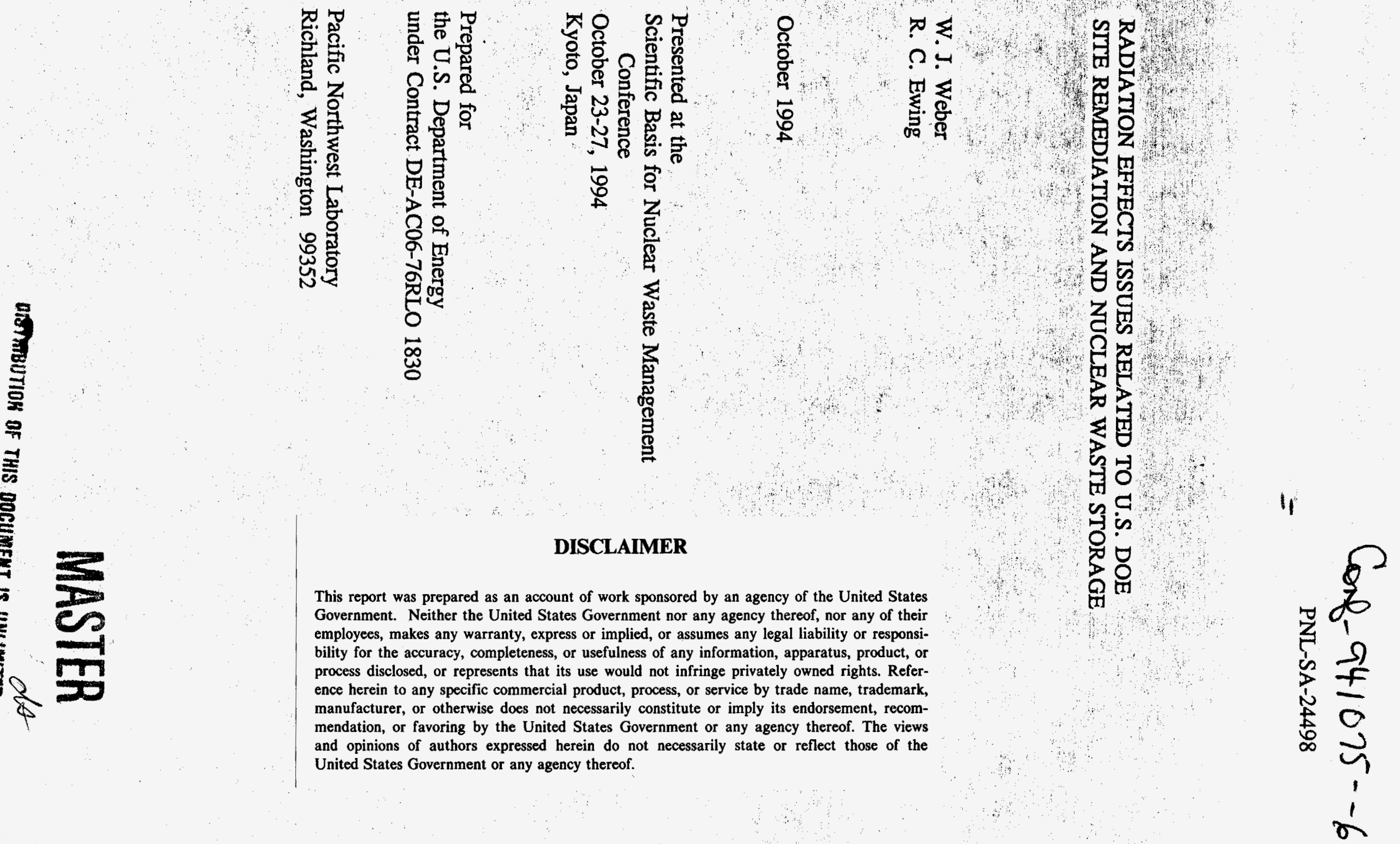


\section{DISCLAIMER}

Portions of this document may be illegible in electronic image products. Images are produced from the best available original document. 


\title{
RADIATION EFFECTS ISSUES RELATED TO U.S. DOE SITE REMEDIATION AND NUCLEAR WASTE STORAGE
}

\author{
William J. Weber ${ }^{*}$ and Rodney C. Ewing** \\ "Pacific Northwest Laboratory, P.O. Box 999, Richland, WA 99352, USA \\ "Department of Earth and Planetary Sciences, University of New Mexico, Albuquerque, NM \\ 87131, USA
}

\begin{abstract}
Site restoration activities at DOE facilities and the permanent disposal of nuclear waste generated at the same DOE facilities involve working with and within various types and levels of radiation fields. Radionuclide decay and the associated radiation fields lead to physical and chemical changes that can degrade or enhance material properties. This paper reviews the impact of radiation fields on site restoration activities and on the release rate of radionuclides to the biosphere from nuclear waste forms.
\end{abstract}

\section{INTRODUCTION}

The high-level wastes (HLW) from the nuclear weapons, nuclear propulsion, and test reactor programs are currently in temporary storage in hundreds of large storage tanks at several DOE sites as crystalline salts, liquids, and sludges. The ultimate objectives of the U.S. DOE site restoration activities are: 1) the immobilization of the DOE HLW in a stable solid form, which has a low potential for radionuclide release, 2) the permanent disposal of the HLW form in a geologic repository licensed by the Nuclear Regulatory Commission (NRC), and 3) the restoration of the DOE sites to a condition that is safe for use in other activities. In addition, the disposal of the plutonium recovered from nuclear weapons under the Strategic Arms Reduction Treaties is a growing issue in nuclear waste management that has been historically tied to site restoration.

Site restoration at DOE facilities involves working with various levels of radiation fields. The most significant issues regarding radiation effects are associated with the remediation efforts for the high-level tank wastes, the clean-up of high-level radioactive sludge in the fuel storage basins, and the disposal of recovered nuclear weapons material. These remediation activities in high radiation fields range from monitoring and analysis of waste in tank storage and fuel basins; safe retrieval and transfer of high-level waste, sludges, and weapons material to pretreatment facilities; processing of the final waste forms; and permanent disposal of the waste packages in a geologic repository. Current technologies for meeting these objectives are inadequate [1], and the effects of radiation are seldom considered in technology implementation, improvement, or development. Consequently, new technologies and materials will be required that are based on an improved understanding of the interaction of radiation with materials. Such an understanding will lead to radiation-tolerant materials and new classes of materials or technologies that utilize the radiation fields in remediation activities.

The principal sources of radiation at the DOE sites are the actinides and fission-products contained in high-level wastes currently in storage. Alpha decay of the actinide elements and beta decay of the fission products lead to physical (radiation damage) and chemical (transmutations) changes [2]. During site restoration, materials will be exposed to radiation fields that exceed $10^{4} \mathrm{rad} / \mathrm{hr}$. Once the nuclear waste is encapsulated in a final form, such as a borosilicate glass, radioactive decay will decrease the radiation field over geologic time scales. The cumulative alpha and beta decay events that are estimated for Savannah River Plant (SRP) glass, assuming a $25 \mathrm{wt} \%$ waste loading, are shown in Fig. 1 as a function of waste storage time. The cumulative alpha decay dose for a waste form containing $10 \mathrm{wt} \%{ }^{239} \mathrm{Pu}$ recovered from nuclear weapons is plotted for comparison. A waste form containing weapons Pu will experience orders of magnitude higher alpha decay dose than the waste glasses proposed for SRP and other 


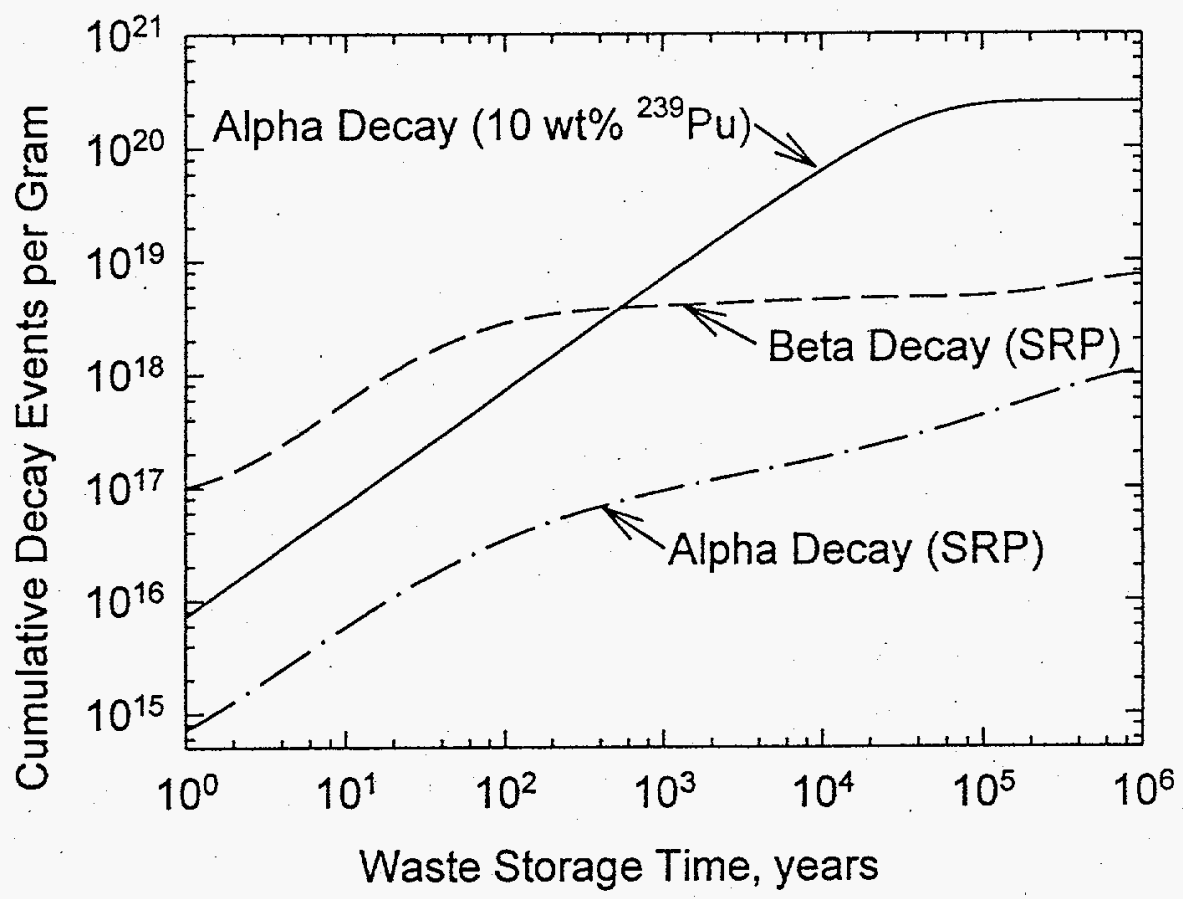

Fig. 1. Cumulative number of decay events per gram for Savannah River Plant waste glass, assuming a $25 \mathrm{wt} \%$ waste loading, and for a waste form containing $10 \mathrm{wt} \%$ recovered weapons plutonium.

DOE wastes. The cumulative dose of absorbed energy for SRP glass as a function of storage time for both alpha and beta decay are given in Fig. 2, along with the dose for a weapons $\mathrm{Pu}$ waste form. The absorbed dose for the $10 \mathrm{wt} \%{ }^{239} \mathrm{Pu}$ waste form is similar to the total (alpha plus beta) dose in SRP glass for the first 40 to 60 years storage. Beyond 60 years, the absorbed dose in a weapons $\mathrm{Pu}$ waste form increases significantly over the total absorbed dose in SRP glass, since the dose rate (activity) changes little in the first 10,000 years storage. Correspondingly, the self-heating for the weapons $\mathrm{Pu}$ waste form will decrease very little during the first 10,000 years.

\section{SITE RESTORATION ISSUES}

Site restoration work at DOE complexes is in its infancy and is expected to take at least 40 years. The technology to carry out much of this work has yet to be developed, with the exception that a waste form (borosilicate glass) has been identified for permanent disposal of the $\mathrm{HLW}$ in a geologic repository. Detailed and accurate characterization of HLW in existing DOE storage facilities is essential to developing appropriate and flexible processes for pretreatment and conversion to a final waste form. Such characterization is also required to classify and certify the HLW for disposal as mandated by state and federal regulations. There is a great incentive to characterize the waste in situ; however, because of the high radiation fields, radiation-resistant probes will be required. Site restoration will also require transfer of HLW to pretreatment facilities and processing of the final waste form and package. In the new open, safety-conscious, and cost-effective culture of DOE, these activities will be closely monitored and the equipment and facilities must be designed to minimize costs and the likelihood of component failures that could pose a hazard to personnel and the environment. As a result, radiation-resistant materials need to be identified at this early stage in the development of technologies necessary for site restoration. Since these technologies are not yet defined, only a few issues are discussed here. For many of these "to-be-developed" technologies, fundamental research is needed to provide the 


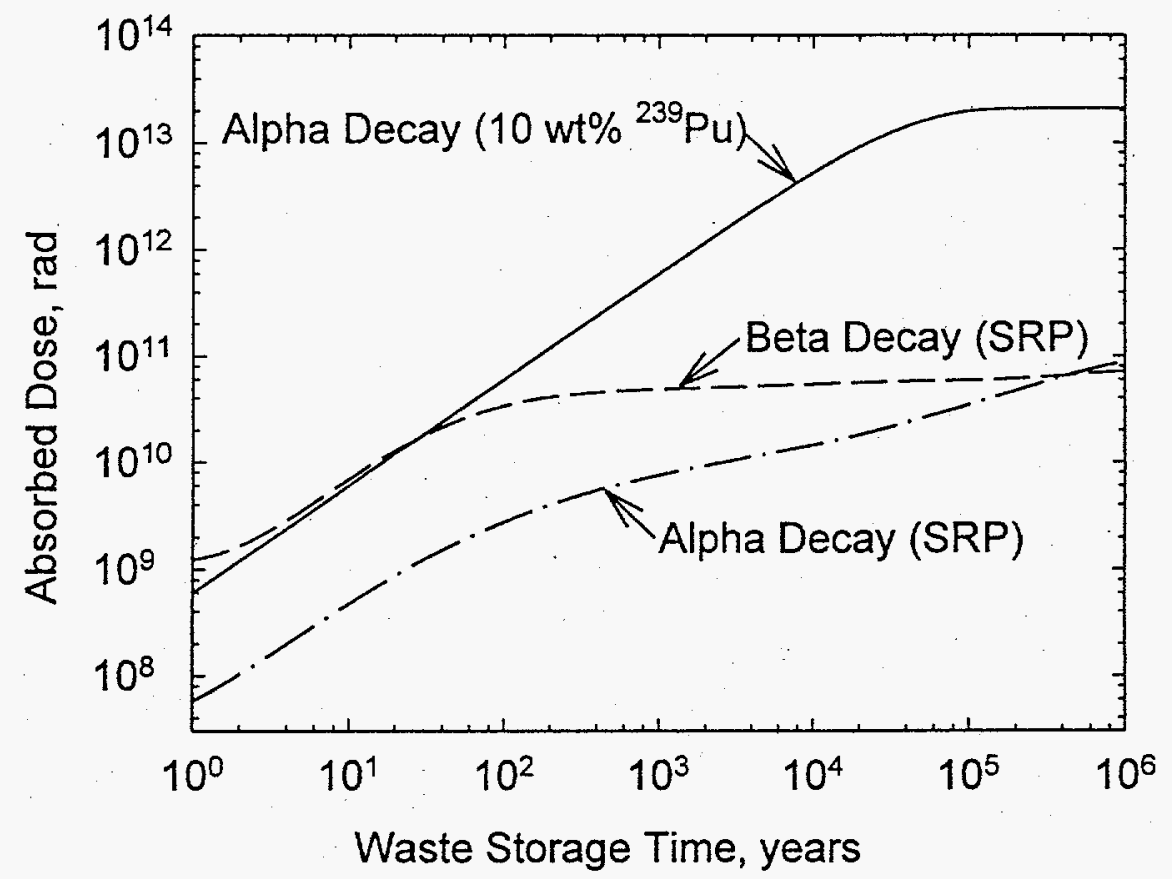

Fig. 2. Cumulative absorbed ionization dose in Savannah River Plant waste glass and in a $10 \mathrm{wt} \% \mathrm{Pu}$ waste form.

underpinning science for timely technology development.

\section{Optical Materials}

Optical materials that can withstand the radiation fields associated with HLW are needed. Fiber optic probes/sensors, which are based on laser-induced emission or scattering techniques; are promising analytical tools for in situ characterization of the HLW in storage tanks, with the potential for a considerable reduction in cost, time, and personnel exposure. Continuous remote monitoring of various radionuclides and chemical compounds in both aqueous and nonaqueous media will be required during HLW pretreatment and conversion processes. The gamma radiation environments, which can exceed $10^{4} \mathrm{rad} / \mathrm{hr}$, in HLW storage and processing facilities produce discoloration within optical materials and the associated loss in light transmission leads to failure of the optical systems employed. The current generation of radiation-hardened optical fibers and glasses degrade rapidly in the high radiation fields associated with HLW; consequently, additional research and development are needed.

\section{Ionization-Induced Electrochemical Reactions}

Photoelectrochemical reactions that rely on electron-hole pair production in stable compounds, such as $\mathrm{TiO}_{2}$, are useful in the oxidation of hydrocarbons, cyanide compounds, and other hazardous compounds, as well as the precipitation of metals and oxides. It is possible that similar reactions can be induced in related compounds by ionization-induced electron/hole pair generation and defect creation. This would allow the use of stable, radiation-resistant materials in many site restoration activities, such as waste retrieval, pretreatment, and water decontamination, by utilizing the radiation environment that is present to activate the materials. Research is needed to advance this technology to practical use.

\section{Ionization-Enhanced Diffusion}

Radiation-enhanced diffusion in materials is generally associated with an enhancement due to the presence of additional defects created by irradiation [3]. Ionizing radiation associated with 
HLW can also enhance or degrade diffusion by several processes. If ionization leads to defect creation by radiolysis or other processes, then diffusion of some species may be enhanced. The more general term "ionization-enhanced diffusion" usually refers to the ionization-induced change in defect charge state that can decrease (or increase) the activation energy for thermally-activated diffusion. Other ionization-enhanced diffusion mechanisms are athermal and associated with electron-hole pairs or other effects of change in charge states [3]. Recent experimental evidence suggests that ionization-enhanced diffusion does occur in ionic materials [4]. These processes could significantly impact a number of site restoration technologies. Ionization-enhanced diffusion could improve separations technology and take advantage of the radiation fields that are inherently present, by identifying separation materials in which enhancement (and not degradation) occurs or by identifying new classes of materials in which enhanced diffusion makes a new separation technology possible. For example, the conversion of neutral defects to charged defects may make separation of some elements possible under an applied electric field that is not feasible in the absence of a radiation field. Ionization-enhanced diffusion in materials is a process that could lead to improved or new technologies for site restoration.

\section{Radiolytic Decomposition}

There are a large variety of crystalline and amorphous solid wastes contained in the HLW tanks and fuel storage basins at the DOE sites. Basic research on the effect of radiation on the structural and bonding properties of these wastes, as well as on equilibria and phase relationships

is needed. Such research would greatly facilitate development of the technology for the safe dissolution and recovery of the solid wastes. Many organic compounds within the HLW tanks at the Hanford site and other DOE sites are undergoing radiolytic decomposition and generating gas. Retrieval of the HLW stored in tanks and the high-level sludge in the fuel storage basins may require that the waste be dissolved and/or stabilized in another form prior to transfer for pretreatment and ultimate disposal. Radiolytic decomposition and gas generation within such interim waste forms is an issue. In addition, radiolytic decomposition of HLW borosilicate glasses may lead to significant alteration of the glass chemistry and microstructure, and radiolytic decomposition of organic compounds and gas generation at repository sites, such as WIPP, is a current safety issue.

\section{DISMANTLED WEAPONS MATERIAL}

A new challenge that is historically tied to site restoration is the disposal of the large quantity of plutonium and highly enriched uranium recovered from dismantled nuclear weapons. With regard to long-term Pu disposition, a recent National Academy of Sciences report [5] recommends three potential options: 1) fabrication and use as fuel in existing or modified reactors; 2) adding the Pu to the HLW stream at DOE sites (Hanford and Savannah River) prior to vitrification; and 3) burial of the $\mathrm{Pu}$ in deep boreholes. The first option creates spent fuel, which could be handled and disposed of along with existing DOE and commercial reactor spent fuel. The second option would increase the actinide content of the proposed nuclear waste glasses by several orders of magnitude. The effects of alpha decay on nuclear waste glasses are not well understood for the currently proposed levels of HLW incorporation; increasing the waste loading of $\mathrm{Pu}$ to proposed levels that may range as high as 5 to $15 \mathrm{wt} \%$ will result in alpha decay damage and ionization doses that exceed by two orders of magnitude the exposures of any simulated waste glasses studied to date. There is no way to use the existing data base, which is already inadequate for proposed HLW glasses, to predict the effects of increased radiation dose in a recovered $\mathrm{Pu}$ waste glass on structural stability, phase transformations, mechanical properties, chemical stability, radionuclide release rates, and ground water radiolysis. The third option (burial in deep boreholes) has not been very thoroughly studied but would only be viable if the $\mathrm{Pu}$ is incorporated into a thermodynamically stable waste form that permits high $\mathrm{Pu}$ loadings. The high waste loading reduces the volume of the waste form. Thermal stability is required due 
to the increased self-heating associated with the high waste loading and the higher temperatures caused by the geothermal gradient. Ceramic waste forms may be more appropriate than borosilicate glass for disposal of the recovered $\mathrm{Pu}$, but ceramics may suffer the temperaturedependent, radiation-induced, periodic-to-aperiodic phase transformation (metamictization), which can cause dramatic changes in physical and chemical properties [6-9].

\section{BOROSILICATE NUCLEAR WASTE GLASSES}

For almost 45 years, scientists have investigated the immobilization and permanent storage of HLW and, from the earliest days, have proposed glasses and ceramics as potential media for $\mathrm{HLW}$ immobilization. Initially, the containment of $\mathrm{HLW}$ in stable waste forms was the primary barrier to release of radionuclides. From about 1977 to 1982 , there was significant effort in the U.S. and abroad on nuclear waste form development, and there was a tremendous diversity in the types of waste forms that were considered [10]. Most of this activity in the U.S. ended with two decisions. First, as a result of political considerations and fuel cycle economics, it was decided that commercial spent nuclear fuel would not be reprocessed, but instead repackaged for direct permanent disposal in a geologic repository [11] Second, on the basis of comparison studies [12], borosilicate glass was selected as the waste form for the disposal of HLW currently stored at the Savannah River Site. Similar comparison studies have not been performed for HLW at the West Valley Project, the Hanford Site, and the Idaho National Engineering Laboratory Site. While these comparison studies have been criticized as incomplete due to the lack of data for alternative waste forms, one of the overriding factors in these decisions was the assessment that the "risk to man" is not significantly affected by the waste form, but is principally controlled by the transport behavior of the radionuclides from the repository [10]. This assessment, which is currently under re-evaluation, formed the basis for the discontinuation of research programs on both alternative waste forms and long-term waste glass behavior, including radiation effects. It is important to note that in current long-term performance assessments, little or no credit is taken for the waste form's ability to contain the radionuclides. If the waste form's ability to retain radionuclides is considered in future performance assessments, then radiation effects are an important consideration.

Borosilicate glass has always been the principal candidate for the immobilization of HLW because: 1) its amorphous structure and strong interatomic bonding allows a wide range of waste compositions to be incorporated into its matrix, 2) it is more durable than other glasses, and 3) it can be processed at lower temperatures. The chemical durability of borosilicate HLW glasses is considered (for regulatory requirements) to be a function of only composition and thermal history [13]; under current management philosophy, the chemical and physical durability of HLW glasses are assumed to be unaffected by radiation. However, the effects of radiation in HLW glasses are complex, and the fundamental understanding of the interactions of radiation with glass is actually very limited. The high-radiation environment provided by the alpha and beta decay of radionuclides in nuclear waste can affect radionuclide release to the biosphere through radiation-induced physical and chemical changes in the HLW glass at both the atomic and macroscopic levels. Several comprehensive reviews [2,10,14-20] of radiation effects in nuclear waste forms provide excellent technical assessments of the field and identify many unresolved scientific and engineering issues regarding radiation effects. The most important unresolved issues fall into three categories: 1) the long-term ( $>1000$ years) effects of alpha decay; 2$)$ the near-term $(<1000$ years) effects of ionizing radiation, particularly from beta decay, on HLW glasses; and 3) the overall effects of alpha, beta, and gamma radiation on radionuclide release.

\section{Effects of Alpha Decay}

Alpha decay will be the dominant source of radiation effects over long-term geologic time scales in HLW glasses and over all time periods for glasses that contain weapons $\mathrm{Pu}$. A considerable amount of data are available on the effects of alpha decay on HLW glasses at 30 
to $40^{\circ} \mathrm{C}$ from studies of actinide-doped glasses [2,10,14-18,21,22]. Since these studies provide valid simulations with both ionizing and displacive interactions from the alpha particles and recoil nuclei, the results accurately reflect expected behavior in actual HLW glass, regardless of whether the dominant damage mechanism is from ionizing or elastic interactions. Alpha decay results in changes in volume, storage of latent energy, microfracturing, decrease in hardness and elastic modulus, increase in fracture toughness, and increases in radionuclide release rates $[18,20]$. A recent study of actinide-doped glass [22] has confirmed the formation of bubbles as the result of alpha decay, and correlated the volume expansion with bubble formation. The major outstanding issue of the long-term effects of alpha decay is the change in radionuclide release rate, since the previous data obtained on actinide-doped HLW glasses may significantly underestimate the actual change $[14,18,20]$. Other issues include the effects of temperature, particularly on bubble formation, and the synergistic effects of shorter-term beta-decay on the longer-term alpha decay effects $[18,20]$. In the case of waste glasses that contain weapons $\mathrm{Pu}$, there is no adequate data base for predicting behavior, since these glasses will be exposed to alpha decay doses (and ionization doses) orders of magnitude higher than any doses achieved in studies to date; in addition, the glass will be at elevated temperatures $\left(>100^{\circ} \mathrm{C}\right)$ for much longer time scales.

\section{Effects of Ionizing Radiation}

As pointed out recently [18], the effect of ionizing radiation from beta decay on HLW glasses is not well understood, and recent evidence suggests that ionization processes from both beta and alpha decay may be the most dominant mechanisms for the degradation of HLW glasses. Early studies of radiation effects in actinide-doped HLW glasses often attributed the radiation-induced changes in glass structure and properties to the displacement damage caused by elastic interactions of the alpha particle and recoil nucleus with atoms within the glass. More recent evidence [18] suggests that radiation-induced volume changes, stored energy, bubble formation, mechanical property changes, and glass decomposition correlate more with the ionizing component of energy deposition than with elastic component.

The early emphasis of radiation effects studies in HLW glasses on displacement damage has led to misconceptions concerning HLW glass stability. Although not originally anticipated; it is now evident that complex borosilicate glasses, including those proposed for the storage of nuclear wastes, can decompose by an ionization-driven radiolytic process that produces molecular oxygen [23-27]. The bubbles that form as a result of this radiolytic decomposition have been observed in a wide variety of glasses irradiated with ions [25-27], electrons [23-30], and gamma radiation $[24,26,27]$. Studies [26,27] utilizing gamma radiation, various ions, and electrons at similar temperatures indicate a significant dose-rate effect for the decomposition and subsequent bubble formation. Bubble formation at ambient temperature $\left(<100^{\circ} \mathrm{C}\right)$ under gamma irradiation begins at $10^{8} \mathrm{rad}$ and saturates at $10^{9} \mathrm{rad}$, which is a much lower in dose than for either ion $\left(10^{9}\right.$ $\left.-10^{12} \mathrm{rad}\right)$ or electron $\left(10^{13}-10^{15} \mathrm{rad}\right)$ irradiations. Under electron irradiation, bubble formation occurs over a broad temperature range with a minimum threshold dose at $250^{\circ} \mathrm{C}[23,27]$. Bubble formation associated with radiolytic decomposition has been correlated with the ionization component of energy deposition and not the atomic displacements [25]. Quantitative studies have shown that the kinetics of the formation process are consistent with the diffusion of alkali metal cations and not oxygen $[23,31]$ The formation of oxygen bubbles is apparently brought about by radiolytic decomposition of the ionic component of the glass, followed by the migration of cations into the glass and the local precipitation of molecular oxygen. Two studies [22,29] have correlated measured volume expansion with the size and density of observed bubbles.

Since this radiolytic decomposition process will be completed in relatively short time for actual HLW glasses ( $<10$ years), the implications of these results may be more serious than previous studies have suggested. In addition, the low-dose nature of this effect underscores the need for an understanding of the temperature dependence of this process, since HLW glasses will be exposed to elevated temperatures and temperature gradients during early storage times. 


\section{Radionuclide Release}

The rate of radionuclide release to the biosphere will, in the first instant, be determined by the release rate from the HLW glass, and in most models of glass corrosion, the release rate is proportional to the surface area. Radiation will affect this release rate by increasing the surface area for radionuclide release (microfracturing or bubble formation), by changing the dissolution rate of the glass, or by enhancing the diffusion of radionuclides to the glass surface. The extent of the radiation-induced microfracturing will depend on differential volume changes, microstructure, and mechanical properties. The dissolution rate of HLW glasses may be affected by the radiation-induced changes in chemistry, microstructure, and bonding. As noted in several reviews $[2,14-16,18,20]$, almost all data concerning the effects of alpha decay on dissolution rates of HLW glasses were determined prior to 1982 in short-term tests based solely on weight loss and, as a result, are probably not a reliable prediction of actual behavior. As discussed elsewhere [18] the best interpretation of this limited data base leads to the conservative estimate that radiation effects are not expected to increase the HLW glass dissolution rates by more than a factor of 10. This estimate is supported by a recent study of a Th-doped borosilicate glass, where the Th daughter product release rate was increased 15 to $45 \%$ due to incongruent dissolution along the recoil tracks produced by alpha decay events [21]. Gamma irradiation of several HLW glasses up to $10^{11} \mathrm{rad}$ also leads to increases in dissolution rates of up to a factor of four [32,33].

\section{CONCLUSIONS}

The development of new technologies for DOE site restoration, including the disposal of recovered weapons $\mathrm{Pu}$, will require fundamental research on the nature and mechanisms of radiation effects in a wide variety of materials to be employed in site restoration activities, as well as in borosilicate nuclear waste glasses or alternative waste forms. Particular attention is needed on the nature of ionization effects on materials, the effects of temperature and dose rate on radiolytic decomposition, the overall effects of alpha, beta, and gamma radiation on radionuclide release, and, for $\mathrm{Pu}$ waste forms, the effects of high-dose alpha-decay damage. At the present time, due to the lack of fundamental scientific understanding and ongoing research programs, the nature, dimensions, implications, and even possible utilization of these radiation effects in site restoration activities remain elusive, particularly with regard to how these effects impact compliance with regulatory criteria for radionuclide release.

\section{ACKNOWLEDGEMENTS}

This work was supported by the Office of Basic Energy Sciences, U. S. Department of Energy under Contract DE-AC06-76RLO 1830 (WJW) and Grant DE-FG03-93ER45298 (RCE).

\section{REFERENCES}

1. 1993 Hanford Site-Specific Science and Technology Plan, DOE/RL-93-38 (National Technical Information Services, Springfield, VA, 1993).

2. W.J. Weber and F.P. Roberts, Nuclear Technology, 60, 178 (1983).

3. J.C. Bourgoin and J.W. Corbett, Radiation Effects, 36, 157 (1978).

4. S.J. Zinkle, Nucl. Instr. and Meth. B91, 294 (1994).

5. Management and Disposition of Excess Weapons Plutonium (National Academy Press, Washington, DC, 1994).

6. W. J. Weber, Radiation Effects, 77, 295 (1983).

7. W. J. Weber, J. W. Wald, and Hj. Matzke, J. Nucl. Mater., 138, 196 (1986).

8. W. J. Weber, J. Am. Ceram. Soc., 76, 1729 (1993).

9. W. J. Weber, R. C. Ewing, and L. M. Wang, J. Mater. Res., 9, 688 (1994). 
10. W. Lutze and R.C. Ewing, in Radioactive Waste Forms for the Future, edited by W. Lutze and R.C. Ewing (North-Holland, Amsterdam, 1988) pp. 699-740.

11. K.S. Kim, in Advances in Ceramics, Vol. 20, Nuclear Waste Management II, edited by D.E. Clark, W.B. White, and A.J. Machiels (American Ceramic Society, Westerville, OH, 1986) pp. 17-28.

12. L.L. Hench, D.E. Clark, and J. Campbell, in Nucl. and Chem. Waste Management, 5, 149 (1984).

13. D.F. Bickford, A. Applewhite-Ramsey, C.M. Jantzen, and K.G. Brown, J. Am. Ceram. Soc., 73, 2896 (1990).

14. W.J. Weber, Nucl. Instr. and Meth., B32, 471 (1988).

15. W.G. Burns, A.R. Hughes, J.A.C. Marples, R.S. Nelson, and A.M. Stoneham, J. Nucl. Mater., 107, 245 (1982).

16. W.G. Burns, A.E. Hughes, J.A.C. Marples, R.S. Nelson, and A.M. Stoneham, in Scientific Basis for Nuclear Waste Management-V, edited by W. Lutze (North-Holland, New York, 1982) pp. 339-348.

17. D.H. Day, A.E. Hughes, J.W. Leake, J.A.C. Marples, G.P. Marsh, J. Rae, and B.O. Wade, Rep. Prog. Phys., 48, 101 (1985).

18. W.J. Weber, JOM, 43 [7], 35 (1991).

19 D. J. Wronkiewicz, Effects of Radionuclide Decay on Waste Glass Behavior - A Critical Review, ANL-93/45 (Argonne National Laboratory, Argonne, IL, 1993).

20. R. C. Ewing, W. J. Weber, and F. W. Clinard, Jr., Progress in Nuclear Energy (in press).

21. Y. Eyal and R.C. Ewing, in Low and Intermediate Radioactive Waste Management, Vol. I, edited by D. Alexandre, R. Baker, R. Kohout, and J. Marek (The American Society of Mechanical Engineers, New York, 1993) pp. 191-196.

22. Y. Inagaki, H. Furuya, K. Idemitsu, T. Banba, S. Matsumoto, and S. Muraoka, in Scientific Basis for Nuclear Waste Management XV, edited by C. G. Sombret (Mat. Res. Soc. Proc. 257, Pittsburgh, PA, 1992) pp. 199-206.

23. J.F. DeNatale and D.G. Howitt, Nucl. Instr. and Meth., B1, 489 (1984).

24. J.F. DeNatale and D.G. Howitt, Radiation Effects, 91, 89 (1985).

25. J.F. DeNatale, D.G. Howitt, and G.W. Arnold, Radiation Effects, 98, 63 (1986).

26. J.F. DeNatale and D.G. Howitt, Am. Ceram. Soc. Bull., 66, 1393 (1987).

27. J.P. Heuer, (M.S. thesis, Department of Mechanical Engineering, University of California at Davis, 1987).

28. A. Manara, P.N. Gibson, and M. Antonini, in Scientific Basis for Nuclear Waste Management- $V$, edited by W. Lutze (North-Holland, New York, 1982) pp. 349-356.

29. S. Sato, K. Asakura, and H. Furuya, Nucl. and Chem. Waste Management, 4, 147 (1983).

30. S. Sato. H. Furuya, K. Asakura, K. Ohta, and T. Tamai, Nucl. Instr. and Meth., B1, 534 (1984).

31. J.Y. Laval and K.H. Westmacott,in Electron Microscopy and Analysis, 1979, edited by T. Mulvey, Conf. Series, No. 52 (Institute of Physics, London, 1980) pp. 295-298.

32. J.R. Grover, in Management of Radioactive Wastes from Fuel Reprocessing (Organisation for Economic Co-operation and Development, Paris, 1973) pp. 593-611.

33. N.E. Bibler, in Scientific Basis for Nuclear Waste Management, edited by S. V. Topp (NorthHolland, New York, 1982) pp. 681-687. 